OLIVEIRA, R.P. et al. Qualidade do leite pasteurizado comercializado no Município de Uberlândia, MG, Brasil. PUBVET, Londrina, V. 5, N. 29, Ed. 176, Art. 1187, 2011.

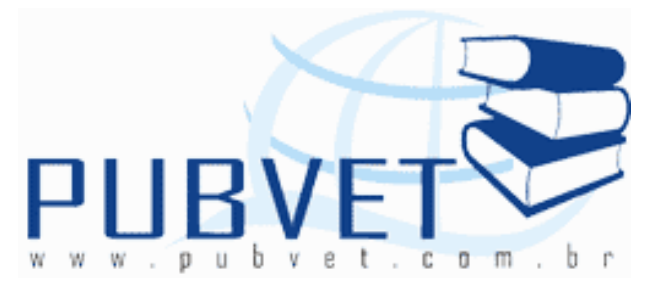

PUBVET, Publicações em Medicina Veterinária e Zootecnia.

\title{
Qualidade do leite pasteurizado comercializado no Município de Uberlândia, MG, Brasil
}

\section{Raquel Peres de Oliveira ${ }^{1 *}$, Mariela Silva Moura $^{1}$, Renata Barbosa Andrade ${ }^{2}$, Silvia Ferreira dos Santos ${ }^{1}$, Mariana Assunção de Souza ${ }^{1}$, Aline Monteiro dos Santos $^{2}$, Ana Carolina Portella Silveira ${ }^{3}$}

${ }^{1}$ Mestranda em Ciências Veterinárias pela Faculdade de Medicina Veterinária, Universidade Federal de Uberlândia. Uberlândia, MG.

${ }^{2}$ Médica Veterinária

${ }^{3}$ Doutoranda do Instituto de Genética e Bioquímica da Universidade Federal de Uberlândia. Uberlândia, MG.

*Autor para correspondência: Rua Ceará, s/n, Bloco 2D, sala 43, CEP 38405303, Uberlândia, MG, Brasil. E-mail: raquelperes_o@yahoo.com.br

\section{Resumo}

A avaliação da contaminação microbiológica do leite é um dos parâmetros importantes para determinar sua vida útil, assegurando saúde dos consumidores. O objetivo deste trabalho foi avaliar as características microbiológicas e físico-químicas de leite pasteurizado comercializado no município de Uberlândia e compará-las com os padrões estabelecidos pela legislação em vigor. Analisou-se 18 amostras, de três marcas de leite pasteurizado coletadas no comércio do município de Uberlândia-MG, realizadas no Laboratório de Controle de Qualidade de Segurança Alimentar, da 
OLIVEIRA, R.P. et al. Qualidade do leite pasteurizado comercializado no Município de Uberlândia, MG, Brasil. PUBVET, Londrina, V. 5, N. 29, Ed. 176, Art. 1187, 2011.

Faculdade de Medicina Veterinária, da Universidade Federal de Uberlândia (LCQSA/ FAMEV/ UFU) nos meses de março e abril de 2009. Observou-se que as análises da fosfatase alcalina, peroxidase, densidade e acidez apresentaram valores normais para todas as amostras. Em relação às outras análises físicoquímicas, os valores não foram satisfatórios, seis $(33,33 \%)$ e nove amostras $(50 \%)$ tiveram resultados inferiores ao mínimo exigido pela legislação para gordura e extrato seco desengordurado respectivamente. E o extrato seco total, 11 amostras $(61,11 \%)$ estavam com valores fora do padrão vigente. Nas análises microbiológicas, para contagem de bactérias aeróbias mesófilas, sete amostras $(38,88 \%)$ apresentaram resultados superiores ao máximo permitido pela legislação, coliformes totais apresentou 13 (72,22\%) amostras acima e coliformes fecais oito amostras $(44,44 \%)$ estavam fora do padrão permitido. Conclui-se que, de modo geral a qualidade do leite tipo $\mathrm{C}$ comercializado no município de Uberlândia-MG no período analisado não foi satisfatória, ou seja, não estavam conforme as normas vigentes principalmente as análises microbiológicas.

Palavras-chave: Análise físico-química, análise microbiológica, lácteo, pasteurização.

\section{Quality of pasteurized milk sold in the city of Uberlandia, MG, Brazil}

\section{Abstract}

The evaluation of microbiological contamination of milk is one of the important parameters to determine their useful life, ensuring health of consumers. The objective of this study was to evaluate the microbiological physicochemical characteristics pasteurized milk sold in the municipality of Uberlândia and compare them with the standards established by law. It was analyzed 18 samples of three brands of pasteurized milk collected in the municipality of Uberlândia-MG, held at the Laboratory of Quality Control of Food Safety, Faculty of Veterinary Medicine, Federal University of Uberlândia (LCQSA / FAMEV / UFU ) in March and April of 2009. It was observed that the analysis of 
OLIVEIRA, R.P. et al. Qualidade do leite pasteurizado comercializado no Município de Uberlândia, MG, Brasil. PUBVET, Londrina, V. 5, N. 29, Ed. 176, Art. 1187, 2011.

alkaline phosphatase, peroxidase, density and acidity showed normal values for all samples. For other physical-chemical analysis, the values were not satisfactory, 6 samples (33.33\%) and 9 samples (50\%) had results below the minimum required by law for fat and dry extract respectively. The total dry extract, 11 samples $(61.11 \%)$ were with values outside the current standard. In the microbiological analysis for enumeration of aerobic mesophilic bacteria, 7 samples (38.88) results were above the maximum permitted by law, total coliform showed 13 (72.22\%) and fecal coliform 8 samples (44.44\%) were outside the permitted standard. It is concluded that in general the quality of type $\mathrm{C}$ milk sold in the municipality of Uberlândia-MG in the period examined was not satisfactory, or not as the rules especially the microbiological analysis.

Keywords: Analysis, physical-chemical, microbiological, milk, pasteurization

\section{Introdução}

O leite está entre os seis produtos mais importantes da agropecuária brasileira, ficando à frente de produtos tradicionais como café beneficiado e arroz. O Agronegócio do Leite e seus derivados desempenham um papel relevante no suprimento de alimentos e na geração de emprego e renda para a população.

A tendência de produção de leite para os próximos anos é de um aumento mundial do volume produzido, principalmente nos países em desenvolvimento onde existem condições climáticas favoráveis para a atividade, permitindo o pastejo dos animais na maior parte do ano, diminuindo os custos de alimentação, mão-de-obra e de capital empregado. Estas tendências indicam uma migração da produção para áreas mais populosas e com menor custo de produção. No Brasil, confirma-se essa tendência de aumento da produção de leite, principalmente nas regiões de cerrado.

Com essa expansão da produção, além da busca por rentabilidade e ganhos de eficiência, é necessária a promoção da saúde humana e animal, garantindo o bem estar animal e sustentabilidade ambiental. Para tanto, é de grande importância, para a qualidade e segurança do leite oferecido aos 
OLIVEIRA, R.P. et al. Qualidade do leite pasteurizado comercializado no Município de Uberlândia, MG, Brasil. PUBVET, Londrina, V. 5, N. 29, Ed. 176, Art. 1187, 2011.

consumidores, as práticas utilizadas durante a produção no campo e dentro das indústrias.

O leite é uma importante fonte alimentar consumida em todo o mundo, por isso, esse leite tem que ser de qualidade, sendo manipulado e inspecionado de forma correta para que a população não consuma um produto de baixa condição sendo um risco para a saúde.

Um método utilizado para melhorar a qualidade do leite é a pasteurização, que consiste no emprego conveniente do calor, com a finalidade de destruir totalmente a flora microbiana patogênica sem alteração sensível da constituição física e do equilíbrio do leite, sem prejuízo dos seus elementos bioquímicos, assim como de suas propriedades organolépticas normais, assegurando a qualidade de conservação do produto.

Existem dois processos de pasteurização: A pasteurização lenta, que consiste no aquecimento do leite a $62-65^{\circ} \mathrm{C}$ por 30 minutos, mantendo o leite sob agitação mecânica, lenta, em aparelhagem própria; e a pasteurização de curta duração, que consiste no aquecimento do leite em camada laminar a 72 a $75^{\circ} \mathrm{C}$ por 15 a 20 segundos, em aparelhagem própria. Logo após esse processo o leite deve ser refrigerado entre $2^{\circ} \mathrm{C}$ a $5^{\circ} \mathrm{C}$ e depois envasado (BRASIL, 1997). A pasteurização, não elimina todos os microrganismos do leite, razão pela qual a vida de prateleira é curta, mesmo sob refrigeração adequada (BRASIL, 2002).

Os serviços de inspeção têm atuando, inspecionando instalações e equipamentos, verificando os procedimentos higiênico-sanitários, fiscalizando o recebimento, manipulação, processamento e conservação dos alimentos, bem como realizando análises sensoriais, físico-químicas e microbiológicas de matéria-prima, ingredientes, aditivos e produtos finais. Vários instrumentos têm sido desenvolvidos e utilizados pelos serviços de inspeção com a finalidade de garantir qualidade aos alimentos, como, por exemplo, as Boas Práticas de Fabricação (BPF) e o sistema de Análise de Perigos e Pontos Críticos de Controle (APPCC) (TIMM et al, 2003). 
OLIVEIRA, R.P. et al. Qualidade do leite pasteurizado comercializado no Município de Uberlândia, MG, Brasil. PUBVET, Londrina, V. 5, N. 29, Ed. 176, Art. 1187, 2011.

Para avaliar se o leite foi corretamente pasteurizado ou se não houve fraudes no produto, é de extrema importância à verificação de alguns testes como os microbiológicos e físico-químicos que são realizados no laboratório da indústria para garantir a segurança do alimento e também para que os mesmos não ofereçam riscos à saúde dos consumidores.

Este trabalho teve como objetivo avaliar os aspectos físico-químicos e microbiológicos de leite pasteurizado no município de Uberlândia-MG, no período de janeiro a fevereiro de 2009, por meio dos testes de Determinação de acidez em graus Dornic, Densidade, Percentagem de Gordura, Extrato seco total, Extrato seco desengordurado e Análises das enzimas Peroxidase e da Fosfatase alcalina, além da contagem padrão em placas, verificação de coliformes totais e fecais de acordo com a metodologia analítica recomendada pelo Ministério da Agricultura, comparando com os padrões estabelecidos pela legislação vigente.

\section{Material e métodos}

Foram colhidas dezoito amostras (todas inspecionadas pelo serviço de inspeção federal), sendo de três marcas diferentes de leite pasteurizado, comercializadas no município de Uberlândia-MG, com intervalo de uma semana entre cada coleta, no período de fevereiro a março de 2009. As amostras foram coletadas em estabelecimento fiscalizado pela Vigilância Sanitária, no período da manhã.

O material foi transportado ao Laboratório de Controle de Qualidade de Segurança Alimentar, da Faculdade de Medicina Veterinária, da Universidade Federal de Uberlândia (LCQSA/ FAMEV/ UFU) em caixa isotérmica contendo gelo.

As análises físico-químicas e microbiológicas foram realizadas logo após a coleta. As análises físico-químicas foram desempenhadas de acordo com a metodologia analítica recomendada pelo Ministério da Agricultura (BRASIL, 2006), e os resultados foram comparados com a instrução normativa n 51 
OLIVEIRA, R.P. et al. Qualidade do leite pasteurizado comercializado no Município de Uberlândia, MG, Brasil. PUBVET, Londrina, V. 5, N. 29, Ed. 176, Art. 1187, 2011.

(BRASIL, 2002). Esses testes compreendem o da densidade, determinação de acidez em graus Dornic, percentagem de Gordura, extrato seco total (EST), extrato seco desengordurado (ESD) e análises das enzimas Peroxidase e da Fosfatase alcalina.

Os testes microbiológicos usados foram realizados através da metodologia analítica recomendada pelo Ministério da Agricultura (BRASIL, 2003), e os resultados foram comparados com a instrução normativa n51 (BRASIL, 2002). Esses testes foram: Contagem Padrão de bactérias aeróbias mesófilas, Determinação do Número mais Provável (NMP) de coliformes totais e fecais.

\section{Resultados e discussão}

Na tabela 1, estão descritos os resultados obtidos das análises físicoquímicas. Os resultados das amostras para densidade e acidez foram todos normais para as três marcas de leite que variam de 1028 a $1034 \mathrm{~g} / \mathrm{ml}$ e 14 a $18^{\circ}$ Dornic respectivamente (BRASIL,2002).

A porcentagem de gordura no leite pasteurizado estabelecido pela legislação deve ser no mínimo 3\% (BRASIL, 2002). No entanto, foram observadas que uma amostra da marca $A(16,66 \%)$, duas amostras da marca B $(33,33 \%)$ e três da marca C (50\%) estavam com valores inferiores ao mínimo.

Em relação ao Extrato seco total, quatro amostras da marca $A(66,66 \%)$, cinco amostras da marca B $(83,33 \%)$ e duas da marca C $(33,33 \%)$ apresentaram valores abaixo do mínimo. O extrato seco total é constituído pelos sólidos total presentes no leite e deve apresentar valores entre 11,5 a $13,5 \%$.

O extrato seco desengordurado deve possuir o valor mínimo de $8,4 \%$ de acordo com o padrão regulamentar (BRASIL, 2002). Verificou-se que quatro amostras da marca A e quatro amostras da marca B $(66,66 \%)$ e uma da marca $C(16,66 \%)$ apresentaram valores menores do que o mínimo exigido. 
OLIVEIRA, R.P. et al. Qualidade do leite pasteurizado comercializado no Município de Uberlândia, MG, Brasil. PUBVET, Londrina, V. 5, N. 29, Ed. 176, Art. 1187, 2011.

Estes valores inferiores ao mínimo estabelecido, tanto do Extrato Seco Total como do Extrato Seco Desengordurado, podem ser um indício de fraude por adição de água, mesmo que os valores da densidade estejam normais já que algumas substâncias como açucares e cloretos quando adicionadas ao leite regulam a densidade, ou pode ser um indício de ausência de padronização de matéria-prima, pois o leite dos animais pode ser afetado pela sua condição física, clima, alimentação, fase de lactação e raça.

As enzimas Peroxidase e Fosfatase alcalina apresentaram valores normais para todas as amostras. A Peroxidase foi positiva indicando que o processo de pasteurização não ultrapassou a temperatura exigida, ou seja, não houve superaquecimento, e a Fosfatase alcalina negativa, indicando que a pasteurização foi efetuada conforme a legislação, pois essa enzima é sensível a esse processo térmico.

Os resultados encontrados para Peroxidase foram satisfatórios. Já os encontrados por Zocche et. al. (2002) na região oeste do Paraná, onde foram observados $30 \%$ dos resultados negativo para a pesquisa da enzima peroxidase. Podendo indicar um superaquecimento durante a pasteurização.

$\mathrm{Na}$ tabela 2 estão descritos os resultados das análises microbiológicas.

O valor máximo de bactérias mesófilas estabelecido pela legislação (BRASIL, 2002), é de 3,0 $\times 10^{5}$ para leite pasteurizado tipo C. Entretanto, verificou-se que quatro amostras da marca $A(66,6 \%)$, duas amostras da marca B $(33,3 \%)$ e uma da marca C $(16,6 \%)$ apresentaram valores acima do padrão estabelecido.

Na determinação do número mais provável de coliformes totais, todas as amostras da marca $A$ apresentou resultados maiores que quatro NMP/mL (BRASIL, 2002), cinco amostras da marca B $(83,3 \%)$ e quatro da marca C $(66,6 \%)$ também obtiveram resultados maiores ao mínimo exigido pela legislação.

Em relação ao número mais provável de coliformes fecais, duas amostras da marca A $(33,3 \%)$, quatro amostras da marca B $(66,6 \%)$ e duas da marca $C$ $(33,3 \%)$ apresentaram valores superiores ao padrão vigente (BRASIL, 2002). 
OLIVEIRA, R.P. et al. Qualidade do leite pasteurizado comercializado no Município de Uberlândia, MG, Brasil. PUBVET, Londrina, V. 5, N. 29, Ed. 176, Art. 1187, 2011.

Tabela 1- Percentual de amostras das marcas A, B e C, dentro e fora dos padrões físico-químicos, de leite tipo $C$ comercializados em Uberlândia, MG, no período de janeiro a fevereiro de 2009.

\begin{tabular}{|c|c|c|c|c|c|c|c|c|c|c|}
\hline \multicolumn{11}{|l|}{ ANÁLISES } \\
\hline \multirow{2}{*}{$\begin{array}{l}\text { FÍSICO- } \\
\text { QUÍMICAS }\end{array}$} & \multicolumn{5}{|c|}{ DENTRO DO PADRÃO } & \multicolumn{5}{|c|}{ FORA DO PADRÃO } \\
\hline & $A$ & $\mathrm{~B}$ & $\mathrm{C}$ & Total & $\%$ & $A$ & $\mathrm{~B}$ & $\mathrm{C}$ & Total & $\%$ \\
\hline Densidade & 06 & 06 & 06 & 18 & 100 & Z & Z & Z & Z & Z \\
\hline Acidez & 06 & 06 & 06 & 18 & 100 & Z & Z & z & z & Z \\
\hline$\%$ Gordura & 05 & 04 & 03 & 12 & 66,66 & 01 & 02 & 03 & 06 & 33,33 \\
\hline$\%$ EST & 02 & 01 & 04 & 07 & 38,88 & 04 & 05 & 02 & 11 & 61,11 \\
\hline$\%$ ESD & 02 & 02 & 05 & 09 & 50 & 04 & 04 & 01 & 09 & 50 \\
\hline Peroxidase & 06 & 06 & 06 & 18 & 100 & Z & Z & Z & Z & Z \\
\hline Fosfatase & 06 & 06 & 06 & 18 & 100 & Z & Z & Z & Z & Z \\
\hline \multicolumn{11}{|l|}{ Alcalina } \\
\hline TOTAL & 06 & 06 & 06 & 18 & 100 & 06 & 06 & 06 & 18 & 100 \\
\hline
\end{tabular}

Até dezembro de 2000, estava em vigor a Portaria 451, do Ministério da Saúde (BRASIL, 1997), que determinava limites para contagem de mesófilos aeróbicos, coliformes totais e coliformes fecais no leite pasteurizado colocado no comércio para consumo humano. Em janeiro de 2001, a Portaria 451 foi revogada pela Resolução nº12 da Agência Nacional de Vigilância Sanitária Anvisa (BRASIL, 2001), que estabelece para o produto em questão a obrigatoriedade de um limite máximo apenas para coliformes fecais e determina a necessidade de uma prova de presença/ausência de Salmonella.

Para efeito de comparação entre a nova legislação e a anterior, os resultados da contagem de coliformes fecais foram confrontados com os padrões estabelecidos pela Resolução n¹2 da Anvisa (BRASIL, 2001), que determina como limite máximo quatro coliformes fecais $/ \mathrm{mL}$. Desta forma duas amostras para a marca A $\left(33,3 \%{ }^{*}\right)$, três amostras da marca B (50\%) e duas da marca C $(33,3 \%)$ apresentaram irregularidades em relação ao padrão que não deve exceder a quatro coliformes fecais/mL segundo a Anvisa (BRASIL, 2001). 
OLIVEIRA, R.P. et al. Qualidade do leite pasteurizado comercializado no Município de Uberlândia, MG, Brasil. PUBVET, Londrina, V. 5, N. 29, Ed. 176, Art. 1187, 2011.

Zocche et. al. (2002) constataram em seu trabalho que $37,5 \%$ das amostras analisadas estavam com os índices de gordura fora dos padrões estabelecidos pela legislação para o leite tipo " $C$ ".

Tabela 2- Percentual de amostras das marcas A, B e C, dentro e fora dos padrões microbiológicos, de leite tipo $C$ comercializados em Uberlândia, MG, no período de janeiro a fevereiro de 2009.

\begin{tabular}{|c|c|c|c|c|c|c|c|c|c|c|}
\hline \multicolumn{11}{|l|}{ ANÁLISES } \\
\hline \multirow{2}{*}{$\begin{array}{l}\text { MICRO- } \\
\text { BIOLÓGICAS }\end{array}$} & \multicolumn{5}{|c|}{ DENTRO DO PADRÃO } & \multicolumn{5}{|c|}{ FORA DO PADRÃO } \\
\hline & $A$ & $B$ & $\mathrm{C}$ & Total & $\%$ & $A$ & $B$ & $\mathrm{C}$ & Total & $\%$ \\
\hline $\begin{array}{l}\text { Aeróbios } \\
\text { mesófilos }\end{array}$ & 02 & 04 & 05 & 11 & 61,11 & 04 & 02 & 01 & 7 & 38,88 \\
\hline $\begin{array}{l}\text { Coliformes } \\
\text { totais }\end{array}$ & z & 02 & 03 & 05 & 27,77 & 06 & 04 & 03 & 13 & 72,22 \\
\hline $\begin{array}{l}\text { Coliformes } \\
\text { fecais }\end{array}$ & 04 & 02 & 04 & 10 & 55,55 & 02 & 04 & 02 & 8 & 44,44 \\
\hline TOTAL & 06 & 06 & 06 & 18 & 100 & 06 & 06 & 06 & 18 & 100 \\
\hline
\end{tabular}

Beloti et. al. (1996), analisando o leite pasteurizado na cidade de Londrina, PR, verificaram que $15 \%$ das amostras estavam fora do padrão estabelecido para a prova de acidez, 5\% para gordura, 22,5\% para densidade, $5 \%$ para ESD, e 2,5\% para peroxidase.

Em um trabalho realizado em João Pessoa - PB, analisando duas marcas de leite pasteurizado, concluíram que $65,63 \%$ das amostras de uma marca A e $32,25 \%$ das amostras de uma marca $B$ se encontraram fora dos padrões vigentes para coliformes totais. Em relação a coliformes fecais, 34,38\% das amostras da marca A e $6,25 \%$ da marca $B$ também estavam fora dos padrões legais (LEITE, 2000).

Os resultados encontrados para contagem de bactérias mesófilas foram inferiores aos encontrados por Carvalho et al. (2004) que apresentou em seu trabalho, $86,7 \%$ de leite pasteurizado fora dos padrões, analisando leite tipo " $C$ " proveniente de uma mini-usina da cidade de Patos, Paraíba. 
OLIVEIRA, R.P. et al. Qualidade do leite pasteurizado comercializado no Município de Uberlândia, MG, Brasil. PUBVET, Londrina, V. 5, N. 29, Ed. 176, Art. 1187, 2011.

Em estudos realizados em Ponta Grossa - Paraná mostrou que 12\% das amostras de leite tipo " $\mathrm{C}$ " analisadas estavam fora dos padrões para extrato seco desengordurado e 16\% para densidade. Em relação a acidez, assim como nesse trabalho, todas as amostras estavam dentro dos parâmetros legais (PEREIRA et al., 2006).

Segundo Riedel (1992) pode ocorrer com certa freqüência a contaminação do leite pós-pasteurização nas fases finais de industrialização, mesmo que os registros automáticos do equipamento de pasteurização estejam funcionando corretamente e indiquem a pasteurização dentro dos limites técnicos recomendados. Essa contaminação final pode ocorrer através da maquina de empacotamento mal higienizada, onde fica restos de leite das operações anteriores, desinfecção nos equipamentos e utensílios da usina, por falta da luz ultravioleta que leva a uma diversidade de microrganismos.

Esses números elevados de bactérias aeróbias mesófilas, coliformes totais e fecais podem ser indícios de uma recontaminação pós-pasteurização de falhas na higiene de beneficiamento, limpeza e desinfecção insuficientes de embalagens e locais de armazenamento ou ainda temperaturas impróprias na conservação do produto. È sugestivo também, pela grande quantidade de microrganismos que podia já estar presente no leite cru, devido à falta do emprego de medidas de Boas Práticas de Fabricação, e por isso o processo de pasteurização não conseguiu eliminar a quantidade máxima de bactérias permitidas no leite pasteurizado, já que a matéria prima estava muito contaminada.

Os resultados obtidos indicam que as rotinas de limpeza e santificação precisam ser revistas e aperfeiçoadas, sugerindo que as atenções sejam maiores em relação à limpeza e desinfecção de máquinas e equipamentos que entram em contato com o leite após a pasteurização.

\section{Conclusão}

Tendo em vista os resultados obtidos nesse trabalho, verifica-se que, de modo geral a qualidade do leite tipo $C$ comercializado no município de 
OLIVEIRA, R.P. et al. Qualidade do leite pasteurizado comercializado no Município de Uberlândia, MG, Brasil. PUBVET, Londrina, V. 5, N. 29, Ed. 176, Art. 1187, 2011.

Uberlândia-MG no período de janeiro a fevereiro de 2009 não foi satisfatória, ou seja, não estavam conforme as normas vigentes principalmente as análises microbiológicas. Todas as amostras foram realizadas dentro dos padrões higiênicos.

Portanto, torna-se evidente a necessidade de programar ações que possam identificar falhas nas atividades de beneficiamento do produto e maior controle na fiscalização pelos órgãos responsáveis, para obter um produto de melhor qualidade e seguro aos consumidores.

\section{Referências}

BELOTI, V.; BARROS, M.A.L.; FREIRE, R.L.; MARTINS, L.G.G.; SOUZA, J.A.; MANDUCA, S.; OSAKI, S. Aspectos Físico-Químicos do Leite Pasteurizado Tipo C Consumido na Cidade de Londrina. In: CONGRESSO BRASILEIRO DE MEDICINA VETERINÁRIA 24. 1996, Goiânia. Anais... Goiânia: Sociedade Goiana de Veterinária, 1996, p.205.

BRASIL. Regulamento Técnico De Identidade e Qualidade De Leite e Produtos Lácteos. Ministério da Agricultura Pecuária e do Abastecimento./ Secretaria Defesa Agropecuária./Departamento de Inspeção de produtos de Origem Animal. Brasília - DF, 1997.

BRASIL. Agência Nacional de Vigilância Sanitária. Regulamento técnico sobre padrões microbiológicos para alimentos. Resolução-RDC n¹2, de 02/01/01.- Anvisa, 2001. Diário Oficial da União, Brasília, 10/01/01, no 7, seção I, p. 45-53, 2001.

BRASIL. Ministério da Agricultura, Pecuária e Abastecimento. Departamento de Inspeção de Produtos de Origem Animal. Instrução Normativa no 51, de 18 de setembro de 2002. Aprova e oficializa o Regulamento Técnico de identidade e qualidade de leite pasteurizado tipo C refrigerado. Diário Oficial da União da República Federativa do Brasil, Brasília, n.172, p.8-13, 20 de setembro de 2002. Seção 1.

BRASIL. Ministério da Agricultura. Secretaria Nacional de Defesa Agropecuária. Laboratório Nacional de Referência Animal. Métodos Analíticos Oficiais para Controle de Produtos de Origem Animal. Brasília, DF, 2003.

CARVALHO, M.G.X.; MEDEIROS, N.G.A.; ALVES, A.R.S.; SANTOS, M.G.O.; LIMA, S.C.P.; AZEVEDO, S.S. Análise microbiológica do leite in natura e pasteurizado tipo " $C$ " proveniente de uma mini-usina da cidade de Patos, Paraíba. Revista Higiene Alimentar, v.18, n.123, p. 6266, 2004.

LEITE Jr., A.F.S.; TORRANO, A.D.M.; GELLI, D.S. Qualidade microbiológica do leite tipo "C" pasteurizado, comercializado em João Pessoa, Paraíba. Revista Higiene Alimentar, v.14, n.74, p.45-49, 2000.

PEREIRA, L.T.P.; ESMERINO, L.A.; SILVA, N.C.C.; CHARNESKI, S.N.; GUZZONI, F.A.; ARAÚJO, A.E. Avaliação dos indicadores de qualidade do leite pasteurizado tipo $C$ comercializado em Ponta Grossa, Paraná. Revista Higiene Alimentar, v.20, n.147, p.83-89, 2006.

RIEDEL,G. Controle Sanitário dos Alimentos. $2^{\circ}$ Ed. São Paulo: Atheneu, 1992. p.320. 
OLIVEIRA, R.P. et al. Qualidade do leite pasteurizado comercializado no Município de Uberlândia, MG, Brasil. PUBVET, Londrina, V. 5, N. 29, Ed. 176, Art. 1187, 2011.

TIMM, C. D.; GONZALEZ, H. L.; OLIVEIRA, D. S.; SCHUSTER, M.; LANSINI, V.; SCHUSTER, C. Retroatividade no serviço de inspeção como instrumento para a melhoria da qualidade do leite. Revista do Instituto de Laticínios Cândido Tostes, Juiz de Fora, v. 58, p. 26-29, 2003.

ZOCCHE, F.; BERSOT, L.S.; BARCELLOS, V.C.; PARANHOS, J.K.; ROSA, S.T.M.; RAYMUNDO, N.K. Qualidade microbiológica e físico-química do leite pasteurizado produzido na região oeste do Paraná. Archives of Veterinary Science, v.7, n.2, p.59-67, 2002. 